Check for updates

Cite this: Mater. Adv., 2021, 2,7473

Received 18th July 2021

Accepted 17th September 2021

DOI: 10.1039/d1ma00621e

rsc.li/materials-advances

\section{Thienyltriazine based conjugated porous organic polymers: tuning of the porosity and band gap, and $\mathrm{CO}_{2}$ capture $\dagger$}

\author{
Neha Rani Kumar, ${ }^{a}$ Prasenjit Das, ${ }^{b}$ Abhijeet R. Agrawal, ${ }^{a}$ Sanjay K. Mandal (DD*b and \\ Sanjio S. Zade iD *a
}

\begin{abstract}
A series of four thiophene and triazine containing conjugated porous polymers (CPPs) comprising the same building block, tris(thienyl)triazine, is synthesized using the alkyne cyclotrimerization reaction for TT-CPP1, Sonogashira coupling reaction for TT-CPP2, Glaser coupling reaction for TT-CPP3 and Stille coupling reaction for TT-CPP4. By varying the spacer between tris(thienyl)triazine units, the porosity (3.6, 4.8 and $5.3 \mathrm{~nm}$, respectively) and the band gap value $(2.43,2.11$ and $2.03 \mathrm{eV}$, respectively) of TTCPP1, TT-CPP2 and TT-CPP3 have been efficiently tuned. All the TT-CPPs display significant thermal stability up to $450{ }^{\circ} \mathrm{C}$. Nitrogen and sulfur of triazine and thiophene moieties, respectively, act as electron-donating centers in these porous polymer frameworks, resulting in excellent adsorption of the Lewis acidic $\mathrm{CO}_{2}$ molecule. A maximum $\mathrm{CO}_{2}$ uptake of $11.4 \mathrm{wt} \%\left(2.6 \mathrm{mmol} \mathrm{g}{ }^{-1}\right)$ at $263 \mathrm{~K}$ under $100 \mathrm{kPa}$ pressure has been observed for TT-CPP1 compared to the other two CPPs due to the small pore size and strong adsorbate-adsorbent interactions. Configurational bias Monte Carlo (CBMC) molecular simulations have shed light on the selective capture, position and binding energy of $\mathrm{CO}_{2}$ for TT-CPP1/2/3.
\end{abstract}

\section{Introduction}

Porous organic polymers (POPs), which include polymers of intrinsic microporosity (PIMs), ${ }^{1}$ hyper-cross-linked polymers $(\mathrm{HCPs}),{ }^{2}$ covalent triazine-based frameworks $(\mathrm{CTFs})^{3}$ and conjugated microporous or porous polymers (CMPs or CPPs), ${ }^{4-6}$ are gaining more recognition compared to their inorganic counterparts as they have inherent remarkable chemical and physical stability along with the possibility to tune their structure. Among these POPs, CPPs are generally synthesized by employing metal-catalyzed cross-coupling reactions that result in the formation of extended $\pi$-conjugated $3 \mathrm{D}$ networks. ${ }^{7} \mathrm{~A}$ judicious selection of the monomer and the polymerization

\footnotetext{
${ }^{a}$ Department of Chemical Sciences and Centre for Advanced Functional Materials, Indian Institute of Science Education and Research (IISER) Kolkata,

Mohanpur 741246, India. E-mail: sanjiozade@iiserkol.ac.in

${ }^{b}$ Department of Chemical Sciences, Indian Institute of Science Education and Research Mohali, Sector 81, Manauli PO, S. A. S. Nagar, Mohali, Punjab 140306, India.E-mail: sanjaymandal@iisermohali.ac.in

$\dagger$ Electronic supplementary information (ESI) available: Procedures for the synthesis of the monomers and polymers, ${ }^{1} \mathrm{H}$ spectra of the precursors and solid-state ${ }^{13} \mathrm{C}$ NMR spectra of TT-CPP4, FTIR spectra of the polymers and their precursors, complete characterization of the polymer TT-CPP4 (morphology, $\mathrm{N}_{2}$ adsorption-desorption isotherm, PXRD, TGA, solid-state UV-vis spectra, KubelkaMunk plot for the band gap) and elemental analysis result of the polymers, FTIR spectra of the polymers after treatment with an acid and a base and ${ }^{1} \mathrm{H}$ NMR spectra of the monomers. See DOI: 10.1039/d1ma00621e
}

conditions or the techniques employed can enable one to have easy control over the physical and chemical properties of CPPs. Another advantage of conjugated porous systems is that various chemical functionalities can be introduced into the pores by employing different organic reactions. ${ }^{7}$ The presence of a rigid $\pi$-conjugated structure imparts these materials with excellent thermal and chemical stability, larger surface areas and tunable porosity. ${ }^{8,9}$ CPPs have received wide attention from the research community for their potential applications in gas storage,${ }^{10-16}$ production of hydrogen,${ }^{17-19}$ catalysis, ${ }^{20-26}$ iodine capture, ${ }^{27}$ light-harvesting, ${ }^{28}$ and supercapacitors. ${ }^{29}$

In the past couple of years, CPPs/CMPs are gaining wide recognition in the field of organic electronics. ${ }^{30,31}$ This necessitates one to have control over their electronic properties because each energy application of this class of materials demands different optimum band gap values: solar cell systems $\left(E_{\mathrm{g}}=1.65-3.27 \mathrm{eV}\right.$ for entire visible-light absorption $){ }^{32} \mathrm{CO}_{2}$ reduction $\left(E_{\mathrm{g}}=1.75-3.0 \mathrm{eV}\right)^{33}$ and water splitting $\left(E_{\mathrm{g}}=1.5-2.5 \mathrm{eV}\right){ }^{34,35}$ To tune the band gap in CPPs, it is necessary to have structural control. However, efforts for such an outcome are significantly less in the literature. One significant contribution in this regard was recently made by Coskun and group, where they reported band gap tailoring via acid-dependent in situ cyclization. ${ }^{36}$

An insight into the literature reveals that the most efficient strategies ${ }^{5}$ to establish structural control in conjugated porous polymers are employed: (i) by controlling the conjugated 
structure and morphology, (ii) by controlling the porous structure, (iii) by tuning the length and geometry of the monomer, (iv) by employing a statistical copolymerization technique, and (v) by tuning the reaction conditions. Furthermore, it is now a well-proven fact that the presence of electron-rich aromatic rings and large heteroatom content can enhance the host-guest interaction of CPPs and boost their overall performance to act as the storehouse of gases. Thiophene, a sulfur-containing aromatic electron-rich heterocycle, is a commonly employed building block in a linear conjugated polymer. However, thiophene containing conjugated porous polymers are significantly less in the literature. ${ }^{3-41}$

Inspired by the above facts and scope, herein, we present the synthesis of a class of thienyltriazine based porous polymers

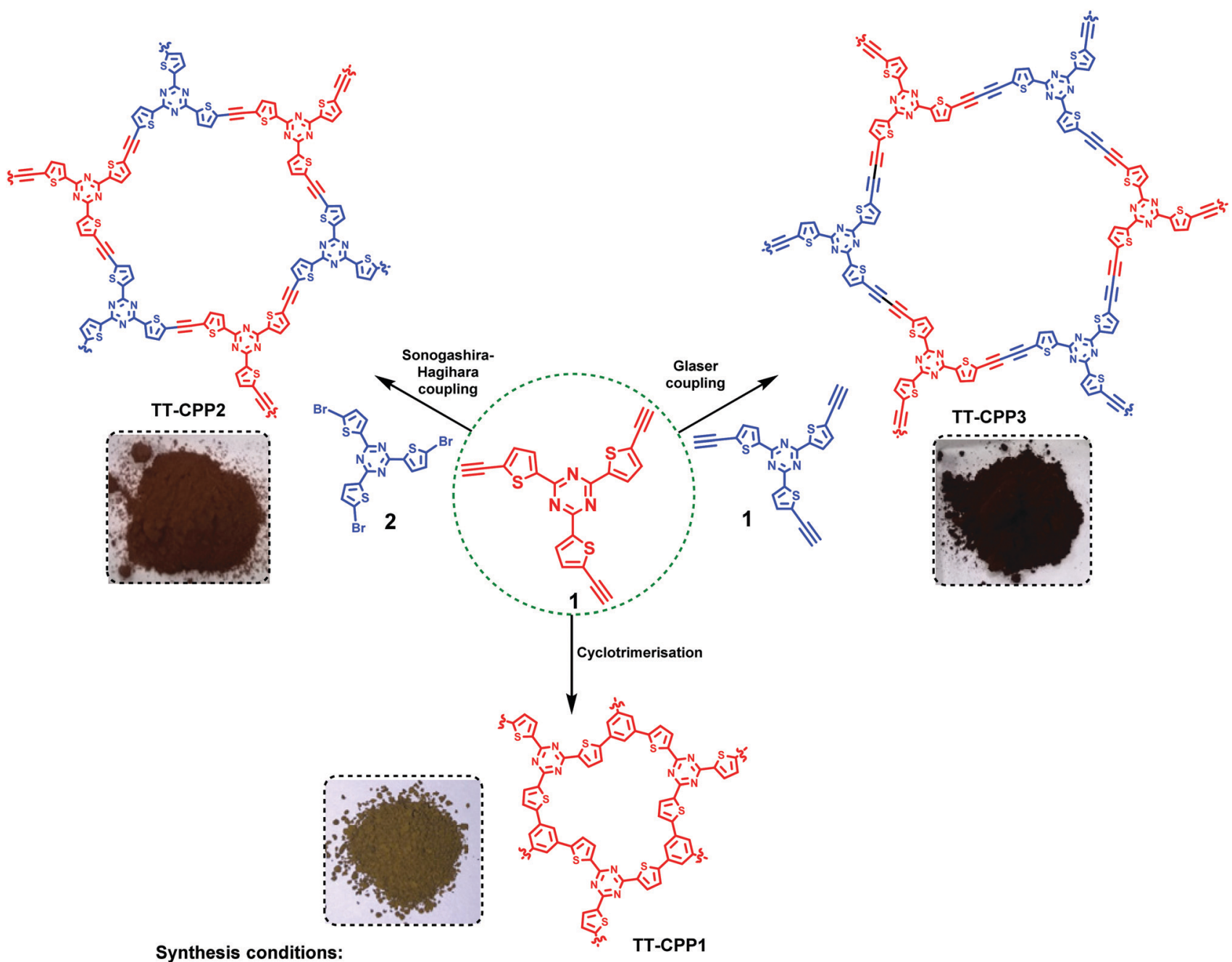

TT-CPP1: Dioxane. $\mathrm{Co}_{2}(\mathrm{CO})_{8}, 100^{\circ} \mathrm{C}, \mathrm{N}_{2}, 1.5 \mathrm{~h}$ TT-CPP2: DMF/Et $\mathrm{H}_{3} \mathrm{~N}(1: 1), 10 \mathrm{~mL}, \mathrm{Pd}\left(\mathrm{PPh}_{3}\right)_{4}, \mathrm{Cul}, 130^{\circ} \mathrm{C}, \mathrm{N}_{2}, 72 \mathrm{~h}$ TT-CPP3: THF/Et ${ }_{3} \mathrm{~N}(1: 1), 10 \mathrm{~mL}, \mathrm{Pd}\left(\mathrm{PPh}_{3}\right)_{2} \mathrm{Cl}_{2}, \mathrm{Cul}, 60^{\circ} \mathrm{C}, \mathrm{O}_{2}, 72 \mathrm{~h}$

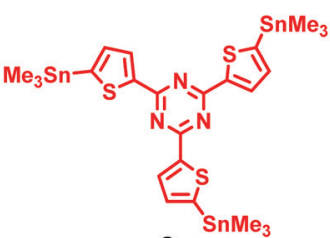

3

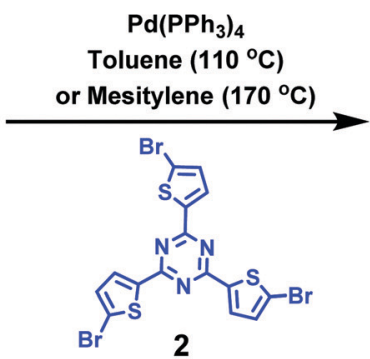

2

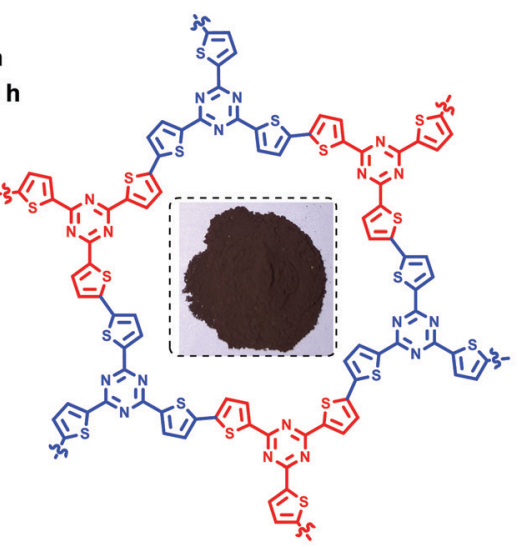

TT-CPP4

Scheme 1 Synthesis of the trithienyltriazine based conjugated porous polymers (TT-CPP1, TT CPP2, TT-CPP3 and TT-CPP4). 
TT-CPP1, TT-CPP2, TT-CPP3, and TT-CPP4 using alkyne trimerization, Sonogashira-coupling, Glaser coupling, and Stille coupling reactions, respectively. The resulting frameworks display high levels of porosity (surface areas up to $545 \mathrm{~m}^{2} \mathrm{~g}^{-1}$ ), stability and $\mathrm{CO}_{2}$ adsorption up to $11.4 \mathrm{wt} \%$. This structural control established over the porous structures is done by efficiently tuning the size and geometry of the building blocks (i.e., by using a spacer) and by tuning the reaction conditions. Their band gaps have also been tuned efficiently.

\section{Results and discussion}

The synthesis of the targeted CPPs was done by using functionalized 2,4,6-tri(thiophen-2-yl)-1,3,5-triazine as the core moiety. The tris(thienyl)triazine core was synthesized starting from 2-cyanothiophene by using the procedure reported by Misra and group. ${ }^{42}$ It was then converted to its triacetylene derivative 1. Scheme 1 outlines the synthesis of TT-CPP1, TT-CPP2, TT-CPP3 and TT-CPP4. TT-CPP1 was synthesized by a $\mathbf{C o}_{2}$ $(\mathrm{CO})_{8}$ mediated alkyne trimerisation reaction of $\mathbf{1}$. TT-CPP2 was synthesized by a Sonogashira coupling reaction of 1 with 2,4,6-tris(5-bromothiophen-2-yl)-1,3,5-triazine (2), whereas TT-CPP3 was synthesized by a Glaser coupling reaction of 1 . On the other hand, TT-CPP4 was synthesized by the Stille coupling of tristannyl derivative 2,4,6-tri(thiophen-2-yl)-1,3,5-triazine ${ }^{43}$ with its tribromo counterpart 2 . Thus, keeping the core moiety intact, we have varied the spacer (benzene, acetylene, and diacetylene) to tune the porosity and band gap energy.

The chemical connectivity and structure of the networks were characterized by Fourier transform infrared (FTIR) spectroscopy (Fig. 1 and Fig. S2, ESI $\dagger$ ), solid state ${ }^{13} \mathrm{C} \mathrm{CP} / \mathrm{MAS}$ NMR spectroscopy (Fig. 2 and Fig. S1, ESI $\dagger$ ), elemental analysis (Table S1, ESI $\dagger$ ) and solid-state UV-visible absorption spectroscopy (Fig. 3a and Fig. S9, ESI $\dagger$ ). The FT-IR spectra show a weak band corresponding to disubstituted $\mathrm{C}-\mathrm{C}$ triple bonds at around $2175 \mathrm{~cm}^{-1}$ in TT-CPP2 and TT-CPP3 (Fig. 1, blue and red spectra). The stretching frequencies around 800, 1370 and $1500 \mathrm{~cm}^{-1}$ confirm the successful incorporation of the $s$-triazine moiety in the polymer frameworks, whereas the peaks at about 3080 and $1625 \mathrm{~cm}^{-1}$ are assigned to $\mathrm{sp}^{2} \mathrm{C}-\mathrm{H}$ stretching and $\mathrm{C}-\mathrm{C}$ double bond stretching of the thiophene ring, respectively (Fig. 1, black, blue and red spectra). The IR spectra also indicate complete attenuation of the peaks at around 2100 and $3400 \mathrm{~cm}^{-1}$ in TT-CPP1-3 involving 1 as the precursor (Fig. 1 and Fig. S3, S4a, ESI $\dagger$ ). There is also a complete disappearance of the $\mathrm{C}-\mathrm{Br}$ band at $1049 \mathrm{~cm}^{-1}$ in TT-CPP2 and TT-CPP4 (Fig. 1 and Fig. S3b, S4b, ESI $\dagger$ ). This confirms their high degree of polymerization.

In the solid-state ${ }^{13} \mathrm{C}$ NMR spectra (Fig. 2), TT-CPP1, TT-CPP2 and TT-CPP3 showed a peak at around 173 ppm, and TT-CPP4 showed a peak at $170 \mathrm{ppm}$, arising from the carbon atoms of the triazine core. The peaks in the range of $84-96 \mathrm{ppm}$ in the spectra of TT-CPP2 and TT-CPP3 are attributed to quaternary alkyne carbons involved in polymerization. The peaks at about 153, 149, 138-135, and 127 ppm correspond to the thiophene carbons,

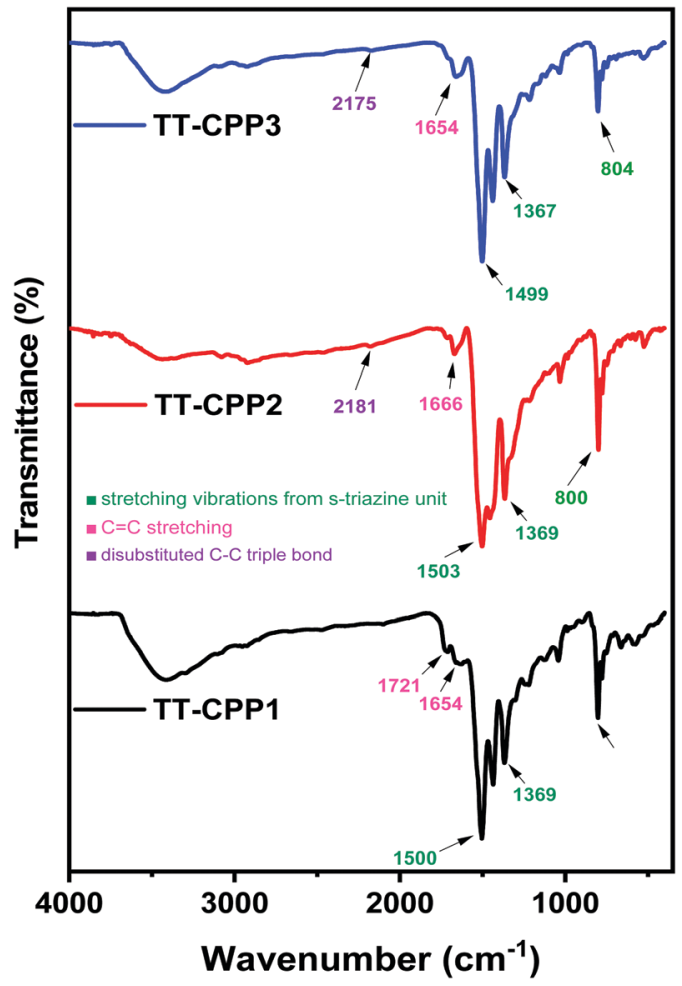

Fig. 1 FTIR spectra of TT-CPP1, TT-CPP2 and TT-CPP3.

where the first peak at $153 \mathrm{ppm}$ corresponds to the thiophene carbon bonded to the triazine ring ( $\alpha$ carbon). The peaks marked with an asterisk in the spectra of TT-CPP2 and TT-CPP3 are the spinning sidebands. By combining the results of FT-IR and solidstate ${ }^{13} \mathrm{C}$ NMR spectroscopy, it can be concluded that the represented polymer skeletons are formed. The experimental values of the $\mathrm{C}, \mathrm{H}$, and $\mathrm{N}$ contents of the polymers in the elemental analysis showed some deviation from the theoretical values due to the presence of unreacted end groups and catalyst residues, as well as trapped gases and moisture, as reported earlier. ${ }^{4-48}$

The solid-state UV-visible spectra of the polymers (Fig. 3 and Fig. S9, ESI $\dagger$ ) showed broad absorption extending from $350 \mathrm{~nm}$ to $800 \mathrm{~nm}$ for TT-CPP2, TT-CPP3 and TT-CPP4, a characteristic of the extended $\pi$-conjugation of the polymer. However, TT-CPP1 also showed an absorption peak in the low energy region extending from $650 \mathrm{~nm}$ to $850 \mathrm{~nm}$. This can be attributed to efficient interlayer stacking between the polymer framework arising probably due to its small pore size, $\pi-\pi$ interaction and presence of sulfur atoms. The Kubelka-Munk plot was used to calculate their band gaps (Fig. 3b-d and Fig. S10, ESI $\dagger$ ). The Kubelka-Munk plot of TT-CPP1 (Fig. 3b) shows a very small hump in the range of 1.5 to $1.8 \mathrm{eV}$ with an onset of the same at $1.5 \mathrm{eV}$ which is due to the interlayer stacking in the polymer framework. Their band-gap values follow the trend TT-CPP3 $<$ TT-CPP2 $<$ TT-CPP4 $<$ TTCPP1. The observed trend is in agreement with the extent of conjugation of the polymers. On moving from polymer TT-CPP1 to TT-CPP2 and TT-CPP3, the color of the polymer powder darkens (Scheme 1), supporting the decreasing band gap and increased $\pi$-conjugation in the same order. 

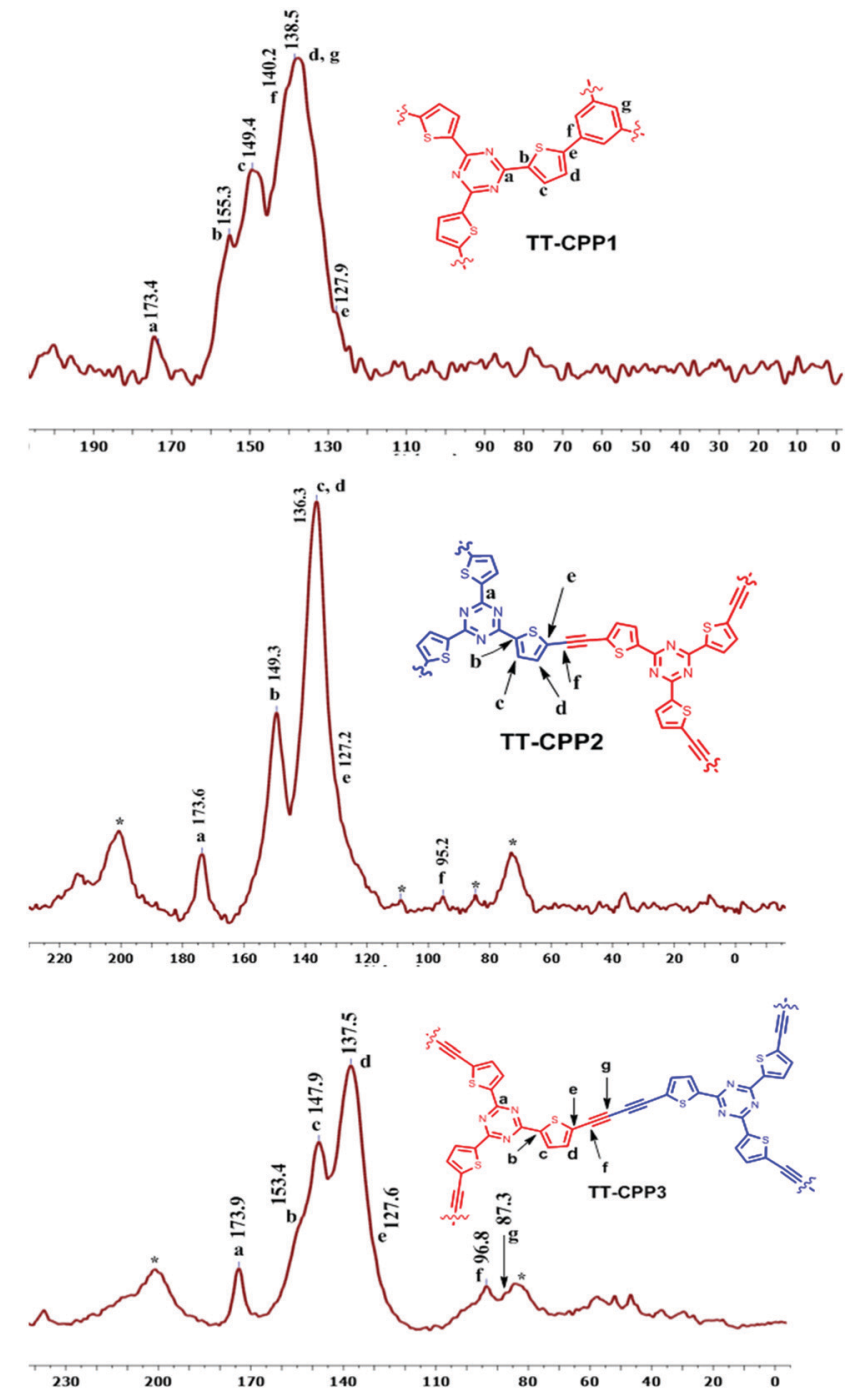

Fig. 2 Solid-state CP-MAS ${ }^{13} \mathrm{C}$ NMR spectra of TT-CPP1, TT-CPP2 and TT-CPP3

The extension of $\pi$-conjugation leads to a decrease in the band gap, and thus TT-CPP3 with the most extended $\pi$-conjugation has the smallest band gap of $2.03 \mathrm{eV}$, whereas TT-CPP1 with the least extension of $\pi$-conjugation has the largest band gap of $2.43 \mathrm{eV}$. This trend can also be attributed to the fact that the incorporation of a compact and rigid carbon-carbon triple bond makes the polymer framework more coplanar, and its electron-withdrawing nature enhances the donor-acceptor nature of the polymer framework, thereby lowering the band gap.

As expected, all the CPPs possess a disordered, amorphous structure, as proven by the broad diffraction peaks in the powder X-ray diffraction measurements (Fig. 4a and Fig. S7, ESI $\dagger$ ). This also supports the fact that the polymerization reactions are kinetically controlled. The high thermal stability of the CPPs was proved by the thermal gravimetric analysis (TGA) measurement (Fig. 4b and Fig. S8, ESI $\dagger$ ). TT-CPP2 and TT-CPP4 retained more than $95 \%$ mass at $500{ }^{\circ} \mathrm{C}$, whereas TT-CPP1 and TT-CPP3 retained more than $85 \%$ mass at $500{ }^{\circ} \mathrm{C}$.
The impressive thermal stability of the polymers can be ascribed to the highly rigid and cross-linked polymer framework. The chemical stability of the TT-CPPs was established by dipping the samples in common organic solvents, an acid and then a base for 3 days and then recording their FTIR spectra. Compared to the FTIR spectra of the as-synthesized materials, the polymer skeleton was found to remain intact (Fig. S11, $\mathrm{ESI} \dagger)$.

Scanning Electron Microscopy (SEM) and Transmission Electron Microscopy (TEM) were used to establish the particle size and morphology of these polymers (Fig. 5 and Fig. S5, ESI $\dagger$ ). The SEM image of TT-CPP1 (Fig. 5a and b) showed a spherical particle-like morphology, which was also confirmed by its TEM image. The SEM and TEM images of both TT-CPP2 (Fig. 5d and e) and TT-CPP3 (Fig. $5 \mathrm{~g}$ and $\mathrm{h}$ ) showed a fibrous morphology; the former had fibers of more ordered and uniform structure, and the latter showed a random intertwining (fibrous) porous structure. TT-CPP4 had an undefined morphology of agglomerated lumps (Fig. S5a and b, ESI $\dagger$ ). The HRTEM images (at $20 \mathrm{~nm}$ scale) of all TT-CPPs showed the presence of alternate dark and bright worm-like structures, which is commonly observed in such porous structures (Fig. 5c, f and i). The permanent porosity and the pore size distributions of the polymers were studied by nitrogen sorption at $77 \mathrm{~K}$. The adsorption isotherms for all the polymers were a mixture of Type II and Type IV (Fig. 6a) as per the IUPAC classification, and a sharp pore size distribution was observed (Fig. 6b). The uptake of $\mathrm{N}_{2}$ at relatively low pressures $P / P^{\circ}<0.1$ is very low, indicating a low level of microporosity in these CPPs. However, a steep increase in $\mathrm{N}_{2}$ uptake was observed at $P / P^{\circ}=0.9-1$, indicating the dominance of mesopores and macropores. The dominant meso- and macropores can arise from the interparticular voids in the porous polymer frameworks. As shown in Table 1, the BET surface area was found to be 545, 511 and $491 \mathrm{~m}^{2} \mathrm{~g}^{-1}$ for TT-CPP1, TT-CPP2, and TT-CPP3, respectively. TT-CPP4 showed a very low surface area of around $5 \mathrm{~m}^{2} \mathrm{~g}^{-1}$, indicating that the Stille coupling reaction is not an efficient synthetic strategy for the synthesis of thienyltriazine based conjugated porous polymers. This has been proven by carrying out the reaction in solvents of different boiling points like THF (reaction temperature kept at $70{ }^{\circ} \mathrm{C}$ ), toluene (reaction temperature kept at $110{ }^{\circ} \mathrm{C}$ ) and mesitylene (reaction temperature kept at $170{ }^{\circ} \mathrm{C}$ ). All the polymers obtained were non-porous except in the case when mesitylene was used as a solvent. However, the surface area obtained was very low. Therefore, considering the inefficiency of the Stille coupling reaction in this particular case, the polymer TT-CPP4 was excluded from establishing the structure-property relationship. Guipeng $\mathrm{Yu}$ and group reported the template assisted synthesis of a nanotubular porous polymer having a structure similar to TT-CPP4. They synthesized the polymer by using the Yamamoto coupling reaction and the BET specific surface area was found to be $741 \mathrm{~m}^{2} \mathrm{~g}^{-1}$. ${ }^{44}$ The decreasing trend of the surface area from TT-CPP1 to TT-CPP3 can be attributed to the increasing size/ length of the linker/spacer if the thienyltriazine system is viewed as the core. In TT-CPP1 the linker is a benzene ring, 

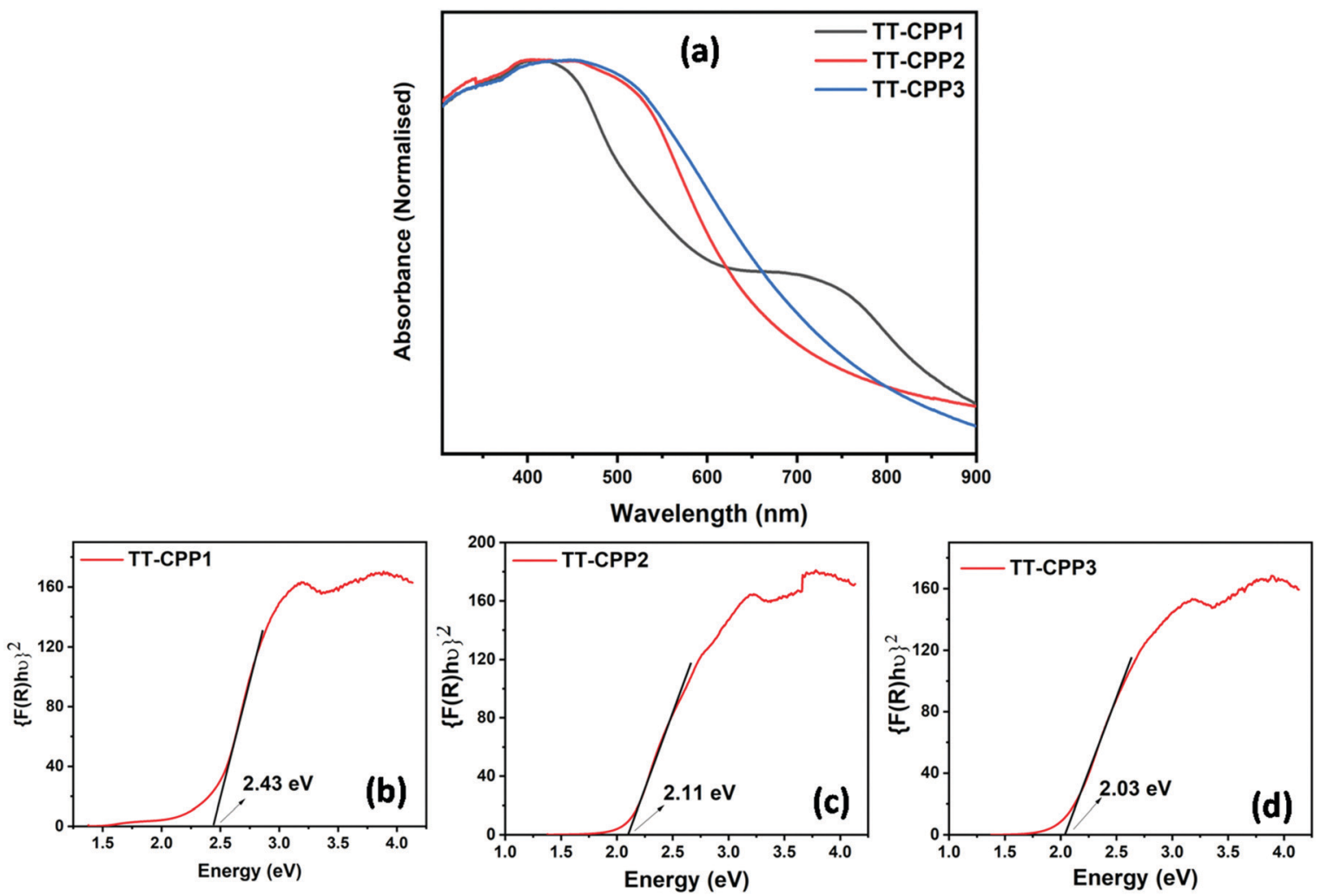

Fig. 3 (a) Solid-state UV-visible spectra of TT-CPPs, and (b-d) Kubelka-Munk plot for the band gap calculation of TT-CPP1, TT-CPP2, and TT-CPP3, respectively.
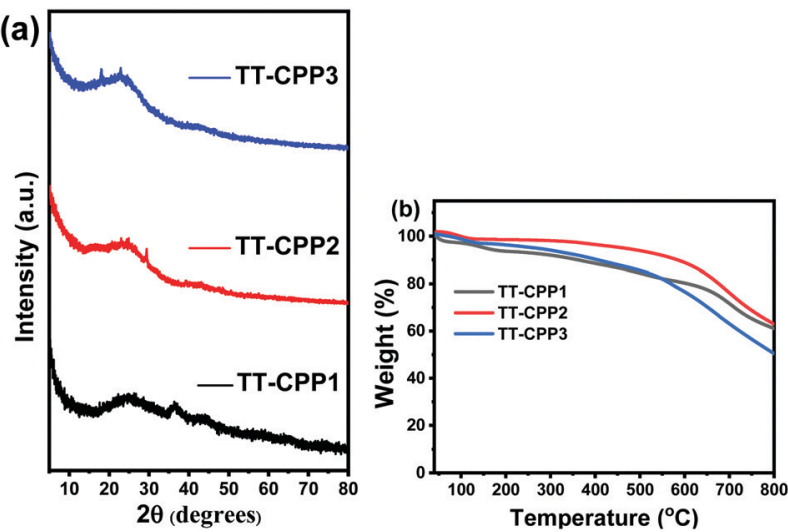

Fig. 4 (a) Powder diffraction patterns of the TT-CPPs, and (b) TGA profiles of the TT-CPPs.

whereas in TT-CPP2 and TT-CPP3 the linkers are acetylene and diacetylene, respectively.

The total pore volume at a relative pressure of $P / P^{\circ}=0.99$ was found to be $0.19,0.63$, and $0.38 \mathrm{~cm}^{3} \mathrm{~g}^{-1}$ for TT-CPP1, TT-CPP2, and TT-CPP3, respectively. The average pore diameter obtained using nonlocal density functional theory (NLDFT) demonstrates that the mesopores are centered in the 3 to $6 \mathrm{~nm}$ range for all the polymers. The expected trend for the pore size as well as the surface area of the polymers is in agreement with the experimentally observed trend.
The polymer TT-CPP1 was previously reported by Wang ${ }^{49}$ and co-workers in 2018 by direct-arylation polymerization. They reported a specific surface area of $74.9 \mathrm{~m}^{2} \mathrm{~g}^{-1}$ and $192.8 \mathrm{~m}^{2} \mathrm{~g}^{-1}$ for TT-CPP1 when the ratio of the thienyltriazine precursor and tribromo benzene precursor was 1 and 1.5, respectively. This polymer was also used for the photocatalyzed oxidative coupling of benzylamine. Its synthesis by a different reaction strategy in our case led to a 2.5 fold increase in the surface area $\left(595 \mathrm{~m}^{2} \mathrm{~g}^{-1}\right)$. This also explains the possibility of using the synthesized polymer as a photocatalyst with better efficiency. The morphology in our case was a spherical particle shape for TT-CPP1. In contrast, Wang et al. reported a fibrous morphology for the same polymer, thus depicting the effect of the reaction conditions on the morphology.

These findings show directions to efficiently tune the electronic structure as well as the band gap values (Fig. 7) in CPPs by careful selection of the monomer and varying the linker/ spacer. In this case, by using an efficient heteroatom rich monomer and by varying the spacer, not only the porous characteristics such as the surface area and pore diameter but also the band gap value have been engineered, showing successful structural control (Fig. 7).

Conjugated porous polymers are finding a wide range of applications. However, they are gaining special recognition as $\mathrm{CO}_{2}$ sequestration materials. ${ }^{50} \mathrm{CO}_{2}$ is one of the major greenhouse gases and is a well-known cause of the adverse effects of global warming. ${ }^{51}$ The $\mathrm{CO}_{2}$ adsorption isotherms of TT-CCP1, 

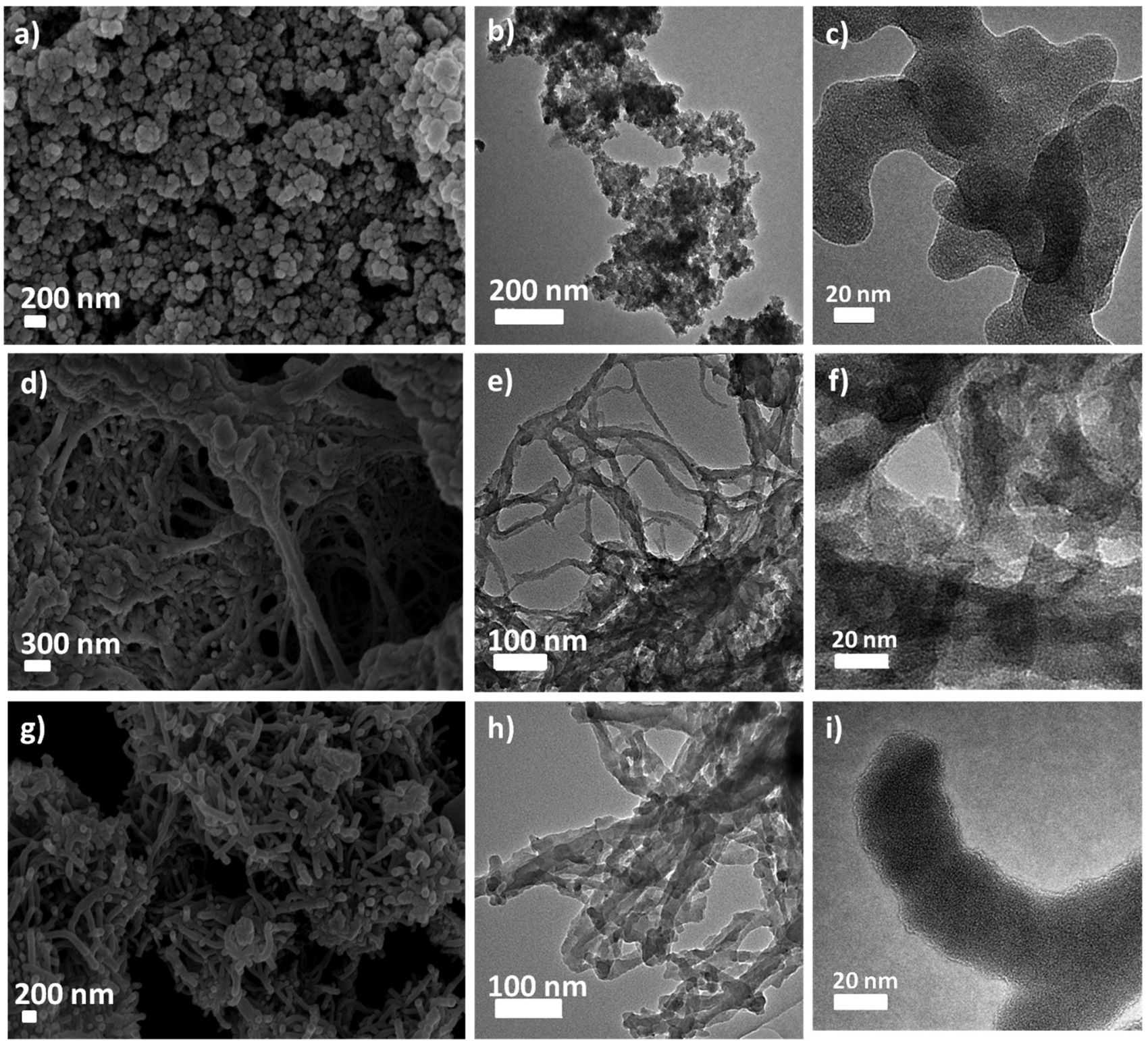

Fig. 5 SEM (a, $d$ and g), TEM ( $b$, e and h) and HRTEM ( $c$, f and i) images of TT-CPP1, TT-CPP2, and TT-CPP3, respectively.

TT-CPP2 and TT-CPP3 at 263, 273, and at $298 \mathrm{~K}$ are illustrated in Fig. 8. As shown in Table 1, their $\mathrm{CO}_{2}$ adsorption capacities
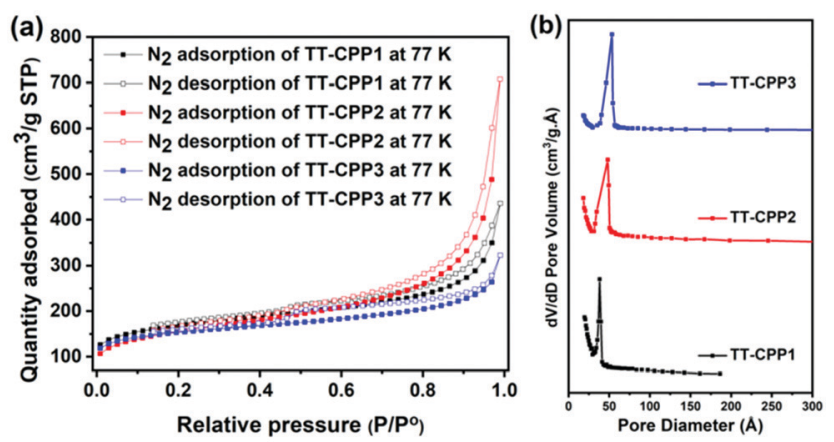

Fig. 6 (a) $\mathrm{N}_{2}$ adsorption-desorption isotherm of the TT-CPPs at $77 \mathrm{~K}$, and (b) pore-size distribution curve of the TT-CPPs. are calculated as $11.4 \mathrm{wt} \%\left(2.6 \mathrm{mmol} \mathrm{g}^{-1}\right), 7.1 \mathrm{wt} \%\left(1.63 \mathrm{mmol} \mathrm{g}^{-1}\right)$, and $5.3 \mathrm{wt} \%\left(1.22 \mathrm{mmol} \mathrm{g}^{-1}\right)$ at $263 \mathrm{~K} / 100 \mathrm{kPa}$ for TT-CPP1, TT-CPP2, and TT-CPP3, respectively (Fig. 8a-c). The presence of $\mathrm{N}$ and $\mathrm{S}$ heteroatoms in these polymers is responsible for the high $\mathrm{CO}_{2}$ adsorption. Also, quadrupole-quadrupole and dipole-quadrupole interactions between the polymer frameworks and $\mathrm{CO}_{2}$ molecules play an important role. The $\mathrm{CO}_{2}$ adsorption is also enhanced by the presence of increased $\pi-\pi$ interactions in the polymer skeleton due to the interaction between the quadrupole moments of $\mathrm{CO}_{2}$ and the $\pi$-clouds in the materials. The $\mathrm{CO}_{2}$ adsorption trend for the polymers is in agreement with their observed surface area calculated from the $\mathrm{N}_{2}$ sorption isotherm. The high adsorption of $\mathrm{CO}_{2}$ by TT-CPP1 may be attributed to its highest surface area amongst all the polymers, its small pore size and the high percentage of micropore volume. The reversible nature of these isotherms confirms the $\mathrm{CO}_{2}$ adsorption over TT-CPP-1/2/3 to be physisorption in 
Table 1 Porosity parameters of the CPPs studied in the present work

\begin{tabular}{|c|c|c|c|c|c|c|c|c|c|c|c|}
\hline Sample code & $\begin{array}{l}S_{\mathrm{BET}}{ }^{a} \\
{\left[\mathrm{~m}^{2} \mathrm{~g}^{-1}\right]}\end{array}$ & $\begin{array}{l}S_{\text {Langmuir }} \\
{\left[\mathrm{m}^{2} \mathrm{~g}^{-1}\right]}\end{array}$ & $\begin{array}{l}S_{\text {Micro }}{ }^{b} \\
{\left[\mathrm{~m}^{2} \mathrm{~g}^{-1}\right]}\end{array}$ & $\begin{array}{l}\text { Average pore } \\
\text { diameter }(\mathrm{nm})\end{array}$ & $\begin{array}{l}V_{\text {Micro }}{ }^{c} \\
{\left[\mathrm{~cm}^{3} \mathrm{~g}^{-1}\right]}\end{array}$ & $\begin{array}{l}V_{\text {total }}{ }^{d} \\
{\left[\mathrm{~cm}^{3} \mathrm{~g}^{-1}\right]}\end{array}$ & $\begin{array}{l}S_{\text {Micro/BET }} \\
(\%)\end{array}$ & $\begin{array}{l}V_{\text {Micro }} / V_{\text {total }} \\
(\%)\end{array}$ & \multicolumn{3}{|c|}{$\mathrm{CO}_{2}$ uptake $\left(\mathrm{mmol} \mathrm{g}^{-1}\right)$ at $100 \mathrm{kPa}$} \\
\hline TT-CPP1 & 545 & 964 & 252 & 3.6 & 0.132 & 0.196 & 46.23 & 67 & 2.62 & 2.18 & 1.27 \\
\hline TT-СРP3 & 491 & 831 & 273 & 5.3 & 0.141 & 0.383 & 55.30 & 36 & 1.42 & 1.22 & 0.76 \\
\hline
\end{tabular}

${ }^{a} S_{\mathrm{BET}}$ is the surface area calculated from the $\mathrm{N}_{2}$ sorption isotherm. ${ }^{b} S_{\text {Micro }}$ is the microporous surface area calculated from the $\mathrm{N}_{2}$ adsorption isotherm based on the Harkins Jura method. ${ }^{c} V_{\text {Micro }}$ is the microporous volume derived from the $t$-plot. ${ }^{d} V_{\text {Total }}$ is the total pore volume at $P / P^{\circ}=0.996$.

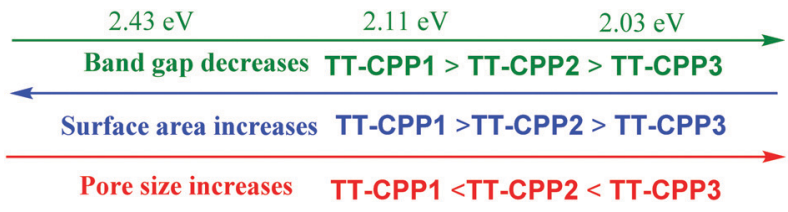

Fig. 7 Tunable properties of the TT-CPPs

nature. The $\mathrm{CO}_{2}$ isotherms measured at 263, 273 and $298 \mathrm{~K}$ were utilized to calculate the isosteric heat of adsorption $\left(Q_{\mathrm{st}}\right)$ by employing the Clausius-Clapeyron equation. Fig. 8d shows a plot of the isosteric heats of adsorption against the $\mathrm{CO}_{2}$ uptake. These $Q_{\mathrm{st}}$ values are below $40 \mathrm{~kJ} \mathrm{~mol}^{-1}$, i.e., the energy of chemical bond formation. This further supports the absence of chemisorption and the presence of strong physisorption of $\mathrm{CO}_{2}$ molecules at the polymer surface containing triazine and thiophene units. The recyclability of $\mathrm{CO}_{2}$ uptake for TT-CPP1 (taken as a representative example) is very good, as evident from the uptake after four consecutive adsorption cycles at $298 \mathrm{~K}$ (Fig. S12, ESI $\dagger$ ). TT-CPP1 with a moderate surface area of $545 \mathrm{~m}^{2} \mathrm{~g}^{-1}$ shows decent $\mathrm{CO}_{2}$ adsorption of $2.18 \mathrm{mmol} \mathrm{g}^{-1}$ at $273 \mathrm{~K}$ and 1 bar if compared to the $\mathrm{CO}_{2}$ adsorption of some best-reported materials such as TPMTP ${ }^{52}$ $\left(S_{\mathrm{BET}}=890 \mathrm{~m}^{2} \mathrm{~g}^{-1}, \mathrm{CO}_{2}\right.$ adsorption: $5.8 \mathrm{mmol} \mathrm{g}^{-1}$ at $273 \mathrm{~K}$ and 1 bar), P-PCz ${ }^{53}\left(S_{\mathrm{BET}}=890 \mathrm{~m}^{2} \mathrm{~g}^{-1}, \mathrm{CO}_{2}\right.$ adsorption: $5.57 \mathrm{mmol} \mathrm{g}^{-1}$ at $273 \mathrm{~K}$ and 1 bar), and HAT-CTF-450/600 ${ }^{54}\left(S_{\mathrm{BET}}=1090 \mathrm{~m}^{2} \mathrm{~g}^{-1}, \mathrm{CO}_{2}\right.$ adsorption: $6.3 \mathrm{mmol} \mathrm{g}^{-1}$ at $273 \mathrm{~K}$ and $1 \mathrm{bar}$ ). Although TT-CPP2 and TT-CPP3 show moderate $\mathrm{CO}_{2}$ adsorption, their adsorption capacity is comparable and even higher in some cases compared to some CPPs reported in the literature with a very high surface area (Table S2, ESI $\dagger$ ).

To gain a clearer understanding of the highly efficient uptake of $\mathrm{CO}_{2}$ for TT-CPP1 over TT-CPP2/3, CBMC molecular simulations in BIOVIA, Materials Studio, have been carried out. At first, TT-CPP1/2/3 containing $(1 \times 1 \times 1)$ hexagonal unit cells has been optimized, and $\mathrm{CO}_{2}$ sorption was performed at $298 \mathrm{~K}$ up to a fixed pressure of 1 bar (Fig. 9). TT-CPP-1 displays strong
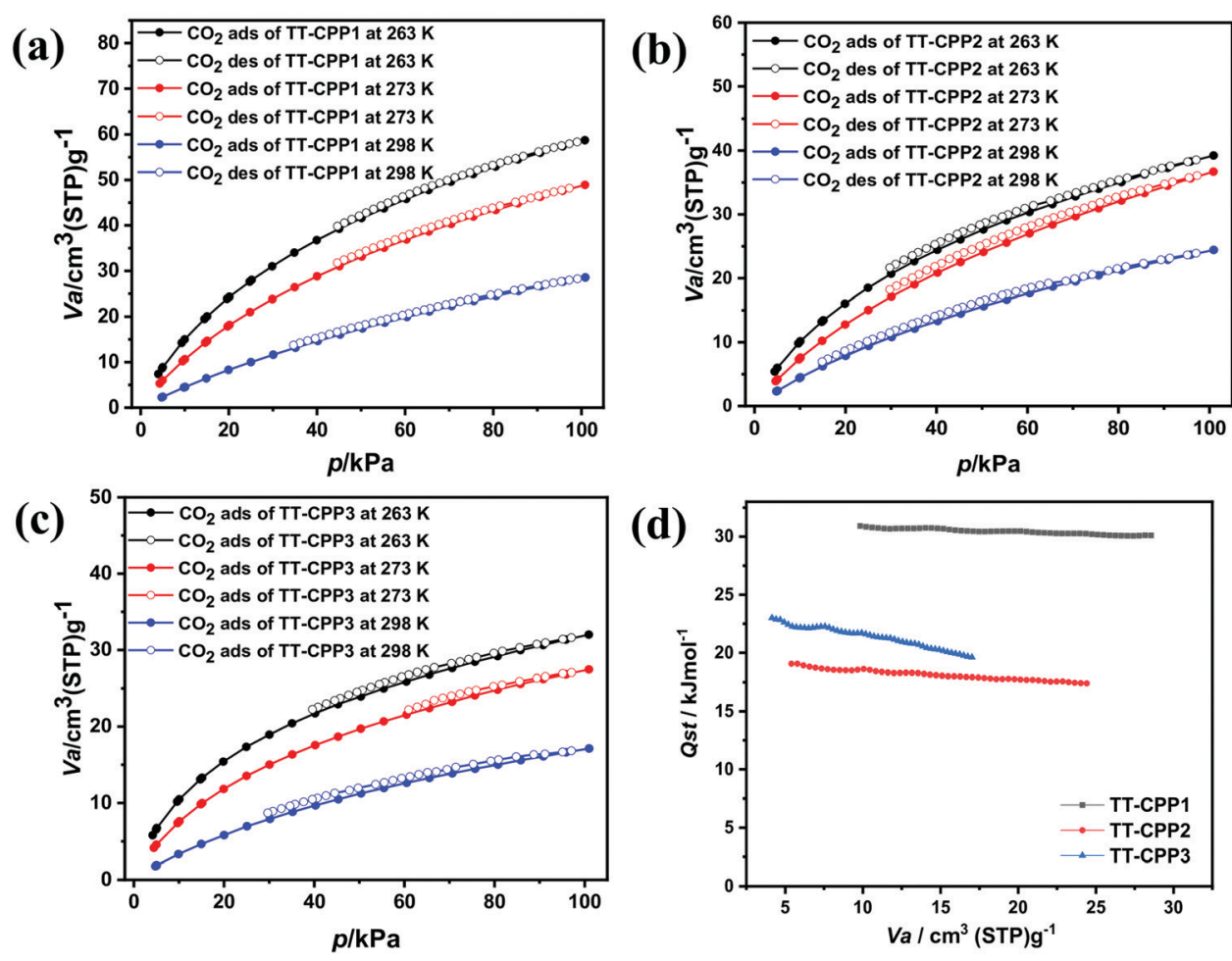

Fig. $8 \mathrm{CO}_{2}$ adsorption-desorption isotherms of (a) TT-CPP1, (b) TT-CPP2 and (c) TT-CPP3 at different temperatures, and (d) $Q_{\mathrm{st}}$ of $\mathrm{CO}_{2}$ for the TT-CPPs 

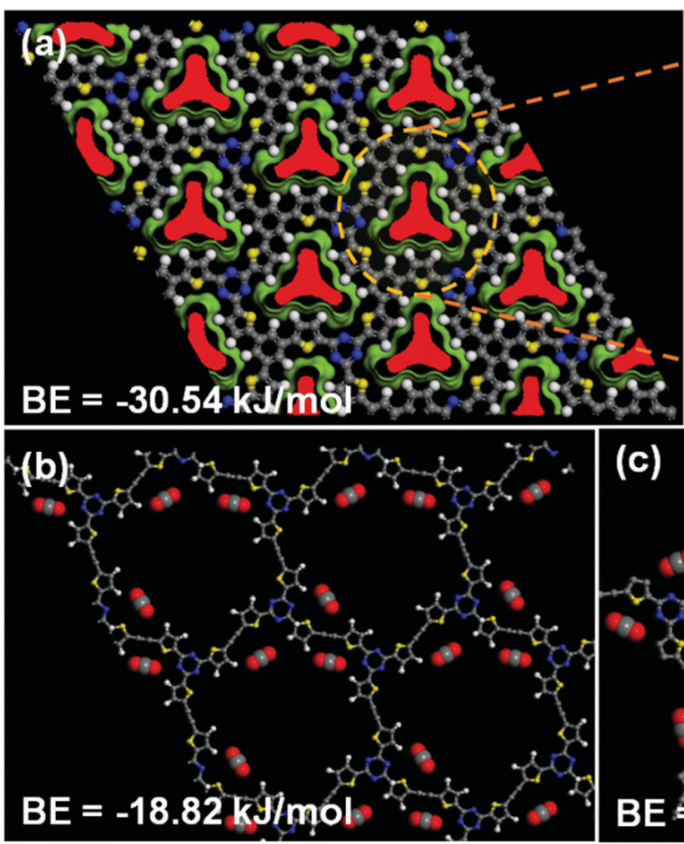

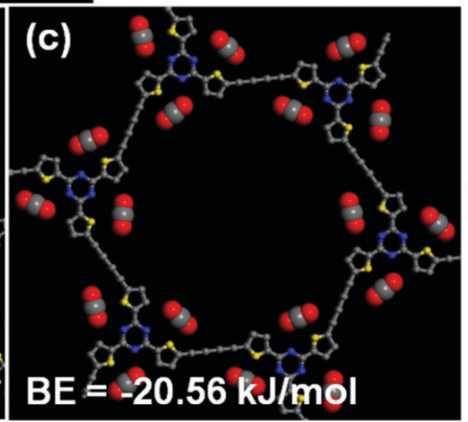

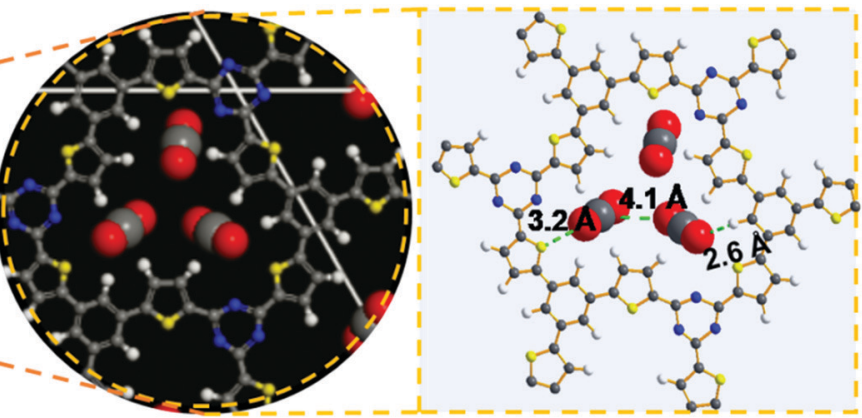

(d)

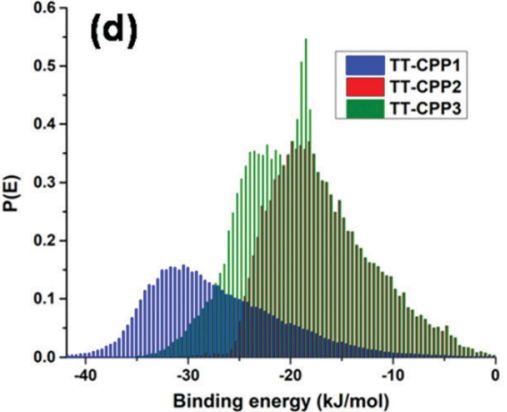

Fig. 9 CBMC molecular simulation: sorption and location of $\mathrm{CO}_{2}$ at $298 \mathrm{~K}$ for (a) TT-CPP1, (b) TT-CPP2 and (c) TT-CPP-3. (d) $\mathrm{CO} 2$ binding energy.

quadrupole-quadrupole and dipole-quadrupole interactions with high binding energy $\left(\mathrm{BE}=-30.5 \mathrm{~kJ} \mathrm{~mol}^{-1}\right)$ compared to TT-CPP2 $\left(\mathrm{BE}=-18.8 \mathrm{~kJ} \mathrm{~mol}^{-1}\right)$ and TT-CPP3 $\left(\mathrm{BE}=-20.6 \mathrm{~kJ} \mathrm{~mol}^{-1}\right)$ (Fig. 9). These $\mathrm{BE}$ values are correlated well with their pore sizes. Both the $\mathrm{C}$ and $\mathrm{O}$ atoms of $\mathrm{CO}_{2}$ interact with $\mathrm{S}$ of thiophene $(\mathrm{S} \cdots \mathrm{O}-\mathrm{C}=3.2 \AA)$ and triazine $\mathrm{N}$ of TT-CPP-1 $(\mathrm{C}-\mathrm{O} \cdots \mathrm{N}=3.6 \AA)$.

\section{Conclusions}

In summary, we describe the synthesis of a series of heteroatom enriched conjugated porous polymers TT-CPP (1-4) based on the thienyltriazine system. Their surface area, pore size and band gap have been tuned efficiently and hierarchically. The CPPs display high thermal and chemical stabilities and high $\mathrm{CO}_{2}$ adsorption, indicating the potential of these polymers in the $\mathrm{CO}_{2}$ sequestration process. TT-CPP1 showed the highest adsorption of about $2.6 \mathrm{mmol} \mathrm{g}^{-1}(11.4 \mathrm{wt} \%)$. The polymers display band gaps in the range of $2.03-2.43 \mathrm{eV}$. This study is relevant for the application of CPPs in organic electronics, optoelectronics, and photochemical water splitting, and the high sulfur content of these materials makes them a potential candidate for application in supercapacitors and lithium-ion batteries. ${ }^{55-60}$

\section{Author contributions}

All authors have given their consent to the final version of the manuscript.

\section{Conflicts of interest}

The authors declare no competing financial interest.

\section{Acknowledgements}

S. K. M. acknowledges IISER Mohali for funding. N. R. K. thanks DST for an INSPIRE fellowship. A. R. A. thanks IISER Kolkata for a fellowship. We also acknowledge TEM, DST-FIST facility, IISER Kolkata, JEM-2100F. SERB, India is acknowledged for funding (CRG/2018/002784).

\section{Notes and references}

1 N. B. McKeown, B. Gahnem, K. J. Msayib, P. M. Budd, C. E. Tattershall, K. Mahmood, S. Tan, D. Book, H. W. Langmi and A. Walton, Angew. Chem., 2006, 118, 1836-1839.

2 S. Xu, Y. Luo and B. Tan, Macromol. Rapid Commun., 2013, 34, 471-484.

3 C. Gu, D. Liu, W. Huang, J. Liu and R. Yang, Polym. Chem., 2015, 6, 7410-7417.

4 G. Cheng, T. Hasell, A. Trewin, D. J. Adams and A. I. Cooper, Angew. Chem., Int. Ed., 2012, 51, 12727-12731.

5 A. I. Cooper, Adv. Mater., 2009, 21, 1291-1295.

6 S. Ren, M. J. Bojdys, R. Dawson, A. Laybourn, Y. Z. Khimyak, D. J. Adams and A. I. Cooper, Adv. Mater., 2012, 24, 2357-2361.

7 Y. Xu, S. Jin, H. Xu, A. Nagai and D. Jiang, Chem. Soc. Rev., 2013, 42, 8012-8031.

8 M. H. Zeng, Q. X. Wang, Y. X. Tan, S. Hu, H. X. Zhao, L. S. Long and M. Kurmoo, J. Am. Chem. Soc., 2010, 132, 2561-2563.

9 A. Laybourn, R. Dawson, R. Clowes, T. Hasell, A. I. Cooper, Y. Z. Khimyak and D. J. Adams, Polym. Chem., 2014, 5, 6325-6333.

10 C. D. Wood, B. Tan, A. Trewin, H. Niu, D. Bradshaw, M. J. Rosseinsky, Y. Z. Khimyak, N. L. Campbell, R. Kirk, E. Stockel and A. I. Cooper, Chem. Mater., 2007, 19, 2034-2048. 
11 J. X. Jiang, F. Su, H. Niu, C. D. Wood, N. L. Campbell, Y. Z. Khimyak and A. I. Cooper, Chem. Commun., 2008, 486-488.

12 C. D. Wood, B. Tan, A. Trewin, F. Su, M. J. Rosseinsky, D. Bradshaw, Y. Sun, L. Zhou and A. I. Cooper, Adv. Mater., 2008, 20, 1916-1921.

13 R. Dawson, D. J. Adams and A. I. Cooper, Chem. Sci., 2011, 2, 1173-1177.

14 P. M. Budd, A. Butler, J. Selbie, K. Mahmood, N. B. McKeown, B. Ghanem, K. Msayib, D. Book and A. Walton, Phys. Chem. Chem. Phys., 2007, 9, 1802-1808.

15 N. B. McKeown, P. M. Budd and D. Book, Macromol. Rapid Commun., 2007, 28, 995-1002.

16 A. Li, R. F. Lu, Y. Wang, X. Wang, K. L. Han and W. Q. Deng, Angew. Chem., Int. Ed., 2010, 49, 3330-3333.

17 X. Wang, K. Maeda, A. Thomas, K. Takanabe, G. Xin, J. M. Carlsson, K. Domen and M. Antonietti, Nat. Mater., 2009, 8, 76-80.

18 X. Wang, K. Maeda, X. Chen, K. Takanabe, K. Domen, Y. Hou, X. Fu and M. Antonietti, J. Am. Chem. Soc., 2009, 131, 1680-1681.

19 M. G. Schwab, M. Hamburger, X. Feng, J. Shu, H. W. Spiess, X. Wang, M. Antonietti and K. Mullen, Chem. Commun., 2010, 46, 8932-8934.

20 F. Goettmann, A. Fischer, M. Antonietti and A. Thomas, Angew. Chem., Int. Ed., 2006, 45, 4467-4471.

21 X. Wang, K. Maeda, X. Chen, K. Takanabe, K. Domen, Y. Hou, X. Fu and M. Antonietti, J. Am. Chem. Soc., 2009, 131, 1680-1681.

22 J. X. Jiang, C. Wang, A. Laybourn, T. Hasell, R. Clowes, Y. Z. Khimyak, J. Xiao, S. J. Higgins, D. J. Adams and A. I. Cooper, Angew. Chem., Int. Ed., 2011, 50, 1072-1075.

23 L. Chen, Y. Yang and D. Jiang, J. Am. Chem. Soc., 2010, 132, 9138-9143.

24 Y. Xie, T. T. Wang, X. H. Liu, K. Zou and W. Q. Deng, Nat. Commun., 2013, 4, 1960.

25 Y. Xie, T. T. Wang, R. X. Yang, N. Y. Huang, K. Zou and W. Q. Deng, ChemSusChem, 2014, 7, 2110-2114.

26 Y. B. Zhou and Z. P. Zhan, Chem. - Asian J., 2018, 13, 9-19.

27 J. Huve, A. Ryzhikov, H. Nouali, V. Lalia, G. Auge and T. J. Daou, RSC Adv., 2018, 8, 29248-29273.

28 L. Chen, Y. Honsho, S. Seki and D. Jiang, J. Am. Chem. Soc., 2010, 132, 6742-6748.

29 Y. Kou, Y. Xu, Z. Guo and D. Jiang, Angew. Chem., Int. Ed., 2011, 50, 8753-8757.

30 J. X. Jiang, A. Trewin, D. J. Adams and A. I. Cooper, Chem. Sci., 2011, 2, 1777-1781.

31 H. Bildirir, V. G. Gregoriou, A. Avgeropoulos, U. Scherf and C. L. Chochos, Mater. Horiz., 2017, 4, 546-556.

32 Z. Sun, N. Talreja, H. Tao, J. Texter, M. Muhler, J. Strunk and J. Chen, Angew. Chem., Int. Ed., 2018, 57, 7610-7627.

33 V. S. Vyas, V. W.-h Lau and B. V. Lotsch, Chem. Mater., 2016, 28, 5191-5204.

34 G. Zhang, Z. A. Lan and X. Wang, Angew. Chem., Int. Ed., 2016, 55, 15712-15727.
35 H. Bohra, S. Y. Tan, J. Shao, C. Yang, A. Efrem, Y. Zhaob and M. Wang, Polym. Chem., 2016, 7, 6413-6421.

36 J. Lee, O. Buyukcakir, T. Kwon and A. Coskun, J. Am. Chem. Soc., 2018, 140, 10937-10940.

37 X. Qian, Z. Q. Zhu, H. X. Sun, F. Ren, P. Mu, W. Liang, L. Chen and A. Li, ACS Appl. Mater. Interfaces, 2016, 8, 21063-21069.

38 H. Bohra and M. Wang, ACS Appl. Polym. Mater., 2019, 1, 1697-1706.

39 W. K. An, S. J. Zheng, Y. N. Du, S. Y. Ding, Z. J. Li, S. Jiang, Y. Qin, X. Liu, P. F. Wei, Z. Q. Cao, M. Song and Z. Pan, Catal. Sci. Technol., 2020, 10, 5171-5180.

40 C. Song, B. Liu, J. Nie, C. Ma, C. Lu, F. Wang, G. Yang and Z. Chen, ACS Sustainable Chem. Eng., 2020, 8, 14377-14385.

41 T. M. Geng, C. Hu, M. Liu, C. Zhang, H. Xu and X. Wang, New J. Chem., 2020, 44, 19663-19671.

42 R. Maragani and R. Misra, Tetrahedron Lett., 2013, 54, 5399-5402.

43 H. Muraoka, M. Mori and S. Ogawa, Phosphorus, Sulfur Silicon Relat. Elem., 2015, 190, 1382-1391.

44 Z. Wang, J. Liu, Y. Fu, C. Liu, C. Pan, Z. Liu and G. Yu, Chem. Commun., 2017, 53, 4128-4131.

45 Y. Xu, D. Chang, S. Feng, C. Zhang and J. X. Jiang, New J. Chem., 2016, 40, 9415-9423.

46 C. Zhang, X. Yang, Y. Zhao, X. Wang, M. Yu and J. X. Jiang, Polymer, 2015, 61, 36-41.

47 R. Dawson, A. Laybourn, Y. Z. Khimyak, D. J. Adams and A. I. Cooper, Macromolecules, 2010, 43, 8524-8530.

48 M. D. W. Hussain, S. Bandyopadhyay and A. Patra, Chem. Commun., 2017, 53, 10576-10579.

49 T. Jin, Y. Xiong, X. Zhu, Z. Tian, D. J. Tao, J. Hu, D. Jiang, H. Wang, H. Liu and S. Dia, Chem. Commun., 2016, 52, 4454-4457.

50 X. Zhu, C. Tian, G. M. Veith, C. W. Abney, J. Dehaudt and S. Dai, J. Am. Chem. Soc., 2016, 138(36), 11497-11500.

51 R. Dawson, A. Laybourn, R. Clowes, Y. Z. Khimyak, D. J. Adams and A. I. Cooper, Macromolecules, 2009, 42, 8809-8816.

52 H. Bohra, P. Li, C. Yang, Y. Zhao and M. Wang, Polym. Chem., 2018, 9, 1972-1982.

53 K. D. Vogiatzis, A. Mavrandonakis, W. Klopper and G. E. Froudakis, Chem. Phys. Chem., 2009, 10, 374-383.

54 S. Hug, L. Stegbauer, H. Oh, M. Hirscher and B. V. Lotsch, Chem. Mater., 2015, 27, 8001-8010.

55 X. Liu, S. Wang, A. Wang, J. Chen, Z. Wang, Q. Zeng, W. Liu, Z. Li and L. Zhang, J. Phys. Chem. C, 2019, 123, 21327-21335.

56 S. K. Kundu, A. Kayet, R. Baidya, L. Satyanarayana and D. K. Maiti, ACS Omega, 2020, 5, 394-405.

57 S. K. Kundu and A. Bhaumik, ACS Sustainable Chem. Eng., 2016, 4, 3697-3703.

58 W. Huang, J. Byun, I. Rcrich, C. Ramanan, P. W. M. Blom, H. Lu, D. Wang, L. C. Silva, R. Li, L. Wang, K. Landfester and K. A. I. Zhang, Angew. Chem., Int. Ed., 2018, 57, 8316-8320. 59 M. E. Bhosale, R. Illathvalappil, S. Kurungot and K. Krishnamoorthy, Chem. Commun., 2016, 52, 316-318.

60 Z. Wang, J. Liu, Y. Fu, C. Liu, C. Pan, Z. Liu and G. Yu, Chem. Commun., 2017, 53, 4128-4131. 